\title{
Work, family life and recovery: An exploratory study of "the third shift"
}

\author{
Ulf Ericsson ${ }^{\mathrm{a}, *}$, Pär Pettersson ${ }^{\mathrm{a}}$, Leif W. Rydstedt ${ }^{\mathrm{b}}$ and Elin Ekelund ${ }^{\mathrm{a}}$ \\ ${ }^{a}$ Work Science, Faculty of Business, Kristianstad University, Kristianstad, Sweden \\ ${ }^{\mathrm{b}}$ Work and Organization Psychology, Norwegian Inland University of Applied Sciences (HHS), \\ Elverum, Norway
}

Received 4 May 2020

Accepted 25 April 2021

\begin{abstract}
.
BACKGROUND: Using 24-hour narratives as a starting-point, the present study examines conditions for recovery from work. The third shift concept forms the explorative starting point for highlighting the interplay between work, family responsibilities, leisure time and recovery.

OBJECTIVE: The aim of the study is to explore how the third shift affects possibilities for recovery.

METHOD: The material was gathered by group interviews and diaries. Thirty employees participated in the study. Ten participants where women between 30 and 45 years of age with children living at home.

RESULTS: Being solely responsible for the third shift reduced the chances of recovery during work-free time. The material showed that women aged 30-45 years had to a greater extent than others the main responsibility in a complex third shift.

CONCLUSION: As a precondition for external recovery, this study show how theoretically beneficial the breakdown of the second shift and development of the third shift is for understanding different preconditions and the way they affect the possibility of recovery.
\end{abstract}

Keywords: Equality, fatigue, stress, women's health, work-life balance

\section{Introduction}

How work and working conditions can affect the health and wellbeing of workers has in recent decades, been the object of intensive attention [1-3, $5,11,40]$. While there is unanimity that working conditions have improved physically in most sectors, the focus has increasingly turned to psychosocial work environment problems. Intensified work demands, and a higher degree of job insecurity and financial unpredictability have evidently contributed to a

\footnotetext{
*Address for correspondence: Ulf Ericsson, Professor, Work Science, Faculty of Business, Kristianstad University, 29188 Kristianstad, Sweden. Tel.: +46 $44 \quad 25032$ 94; E-mail: Ulf.ericsson@hkr.se.
}

higher work-load and stress $[4,10,35]$. There has also been a growing interest in the interaction and balance between work and non-work time, mainly family responsibilities [1, 6, 28]. Frankenhaeuser [14] categorized these two spheres as the first and second shifts.

In this study, the third shift concept, suggested by Hochschild [19, 20] and subsequently by Smeby [33], forms the explorative starting point for highlighting the interplay between work, family responsibilities, leisure time and recovery. Thereby, the field is widened from purely understanding recovery from work (first shift) to also including recovery from unpaid domestic work (second shift) as well as the responsibility for this (here referred to as the third shift). Separating and labelling this the third shift 
enables us to shed light on problems that can't be understood exclusively in terms of time consumption, but also as involving a constant demand for directed attention.

Research on recovery from work should not only study workload quantitatively but also taking into consideration the demands for responsibility and planning [4]. The aim of this study is to illuminate whether demands emanating from "the third shift" can also lead to impaired recovery.

\subsection{Work process cycles}

Regardless whether the demands from work are experienced as strenuous and potentially stressful, or as reasonable and manageable, the work cycle comprises three phases: mobilization, performance and recovery [26, 37]. Mobilization refers to the activation of the physical and mental systems needed to start and accomplish work. To start the work process requires motivation and a conscious act of volition involving energy mobilization and focused concentration [26, 37]. Work implementation can be seen as the individual's investment of physical and mental resources in the work process, whereby the worker aims to gain material and social resources $[5,18]$. Even though the use of resources and the investment of energy are natural prerequisites for human development, the resources consumed by the individual while at work, are limited and transient. Fatigue, decreased motivation, difficulties in maintaining concentration and attention are subjective signals indicating that the individual's resources are on the point of becoming exhausted, which makes the individual wish to interrupt work in order to recover [18, 26, 37].

In research on work-related stress, recovery from work has become a core concept. Initially stress research mainly focused on reactivity (from baseline to peak values in the psycho-physiological parameters) from stress exposure. More recent research has, however suggested, that the speed and the effectiveness of returning to normal values for stress-related mental and psycho-physiological parameters are the key in explaining the health consequences of stress exposure [23-26].

To regain and recreate the physical and mental resources consumed at work requires that the individual has an opportunity to recover. If the lack of recovery is temporary, the consequences are not very serious, and the individual has the possibility to recover. Brief episodes of stress-related activation may be perceived as an adaptive response to the imbalance between the needs of the individual and the external requirements $[25,36]$. Long periods of insufficient recovery where the individual has to keep mobilizing conscious efforts to cope with the demands of work, will however create allostatic load [25], leading to a growing risk of mental and physical health problems [16, 26, 30, 32]. From a resource perspective, a condition of extensive enforced mobilization can be understood as an imbalance, where the loss of energy resources grows bigger than the benefits of work, which can then be interpreted as chronic stress [18].

Geurts and Sonnentag [16] made a distinction between internal recovery, short breaks during ongoing work - and external recovery, taking place on work-free time, weekends, holidays etc. The majority of research in this area has, so far, focused on the effects and consequences of (the lack of) external recovery [e.g 16, 26, 30, 32]. Lately, the interest in the effects of internal recovery during working hours has increased, after recent studies have demonstrated internal recovery to be associated with wellbeing [9, $11,38,39]$.

\subsection{The twenty-four-hour story and recovery from work}

Recovery is a dynamic regulation and adaptation process between the individual activity level and the demands and conditions of the context [37]. The type of stressors from work or in the conflicts between work and other life roles are often low intensity but -daily occurrences and hassles [21, 22].

While high control in work and qualified work tasks is generally seen as beneficial, Aronsson et al. [4] suggests that more complex work demands may lead to difficulties to "let go" of the job during free time and increased work-related rumination, which may interfere with the recovery process [e.g, 8, 12]. Aronsson et al. [4] use the metaphor of "the long arm of the job". By introducing the long arm of home metaphor, we intend to further illuminate the complex interaction between the demands from work on managing the accomplishment and planning of domestic duties.

\subsection{The first, second and third shifts}

Previous researchers who have drawn attention to a more complex relation between work and non-work have highlighted the interplay between the first and 
the second shifts $[19,2018]$. The first shift concerns paid work, while the second deals with the domestic sphere. Earlier studies by Frankenhaeuser [13, 14] showed that the norepinephrine stress hormone in women increased when leaving their workplace (first shift) to go home (second shift), while the contrary applied among males. Frankenhaeuser et al. [15] demonstrated that women, besides reporting that they devoted more time to home work than men, also stated that they were largely responsible for more different domestic tasks.

To understand the mental demands of work performed in the home, Hochschild [19] launched the concept of the third shift. When both partners work full time, limited time and energetic resources may be left for the second shift, the duties at home. The second shift then becomes, more rationalized Hochschild [19]. To compensate for this, parents try to spend brief sessions of quality time with their children to make amends for emotional neglect in everyday life. In Hochschild's study, it was the women who took responsibility for this emotional work at home, the third shift. Smeby [33] develops this concept by splitting the second shift into two parts: implementing, on the one hand, and planning/organizing, on the other. Hence, Smeby supplements Hochschild's third shift by the planning and organizing of the work in the domestic sphere. This definition makes the third shift more subtle and intangible, but at the same time more important for understanding the relation between work, leisure-time demands and possibilities for recovery. The present study is inspired by Hochschild's [19] seminal work with its increasingly complex approach to the relation between different shifts, as well as the description of how the division of responsibility within these shifts affects the individual. However, the third shift concept as used in the present article will rather reflect Smeby's [33] definition, especially the part referring to organizing and planning, including a stronger feeling of responsibility for the second shift.

\subsection{A limited focus and the aim of the study}

Sickness absence have increased rapidly in Sweden during the last decade, primarily due to psychiatric diagnoses, and this is particularly evident among women between 30 and 45 years of age [31]. According to a Statistics Sweden report [34], the time devoted to work and domestic tasks is now more equally distributed, in terms of work hours as well as domestic duties, between women and men compared to the situation when Frankenhaeuser's studies [14, 15] were conducted. It is, although, reasonable to take the burden of responsibility into account when exploring total workload.

The starting point of the present study is the metaphor of the long arm of home. Its aim is to explore how the third shift affects possibilities for recovery. More specifically, the study investigates how the third shift is perceived and constructed and what are its consequences for the recovery process.

\section{Context, material gathering, analysis and presentation}

The study was conducted at two offices in a Swedish major insurance company. The total number of employees at the two offices was 106- 59 females and 47 males, aged between 18 and 65 .

Thirty employees participated in the study. The material was gathered by group interviews and diaries. Five groups were created, representing all levels and departments, including members of the management team. The fifth group, which was created after the initial analysis of the material, consisted solely of women between 30 and 45 years of age who had at least one child living at home. Fifteen of the participants were aged between 30 and 45 years. Out of these 15, 11 were women, ten of whom had children living at home. Twenty participants had children living at home.

The employees were contacted via e-mail containing a brief description of the aim of the study and an invitation to participate. The group interviews were followed by a diary study. Eleven people were asked to participate, all of whom consented. One participant withdrew due to illness. The diary study was concluded by a follow-up conversation.

\subsection{The group interviews}

The researchers performed the group interviews, to ensure that the conversation kept within the framework of the study aim and that each participants were able to tell their story. The group interview started by asking one participant to describe an "ordinary day", from getting up in the morning to going to bed in the evening. This formed the framework for the other participants to comment, ask questions and add their own experiences. The participants' follow-up stories were linked to the first ones by discussing differences and similarities. 
Sometimes, participants' recognition factor of someone else's "ordinary day" was so high that, instead of recounting their whole 24-hour story, they confirmed and further developed someone else's. In those cases, more specific differences and "local" deviations were clarified by the participant. An elementary interview guide was used with only a few themes based on dividing the twenty-four hours into three parts: sleep, work and work-free hours. A further starting point was that the different roundthe-clock activities could be divided into one of the following three emotional and cognitive phases: mobilization, performance and recovery. The participants were also encouraged to identify different situations where they had the specific intention to devote themselves to recovery activities. The researchers were also intent on asking for occasions that might be taken for granted, such as coffee breaks, lunches and sleep. The participants had no problem telling their 24-hour story. The role of the researchers was supporting and facilitating the story-telling and the group talks, by asking follow-up questions, encouraging additions and further contributions. The researchers frequently requested clarification and, above all, concrete examples.

The interviews lasted for one and a half hours, and were recorded and transcribed verbatim. The group interviews were first read through several times to gain an understanding of what the participants reported. The material was then coded into units of meaning comprising a word, a sentence or a paragraph. This was followed by an abstraction process, where the condensed fragments were given more conceptual labels.

\subsection{Diary study and follow-up conversation}

The structure of the diary, inspired by Bergman et al. [7], was designed to highlight the three phases forming the study's theoretical starting point: mobilization, performance and recovery. A total of 10 individuals participated in the diary study: six women and four men, all between 34 and 56 years old. Nine out of ten had children living at home. During the handing out of the diary, two of the researchers met with the participants to explain its different parts. In close connection with the presentation, the participants then filled in the diary. They were asked to make an entry each day of the week. One of its aims was to capture the number and variety of activities performed during one day. Every day was divided into seven different time intervals:
6.30-9.00, 9.00-12.00, 12.00-15.00, 15.00-17.00, $17.00-20.00,20.00-23.00$ and 23.00-06.30. What was recorded in the diary included which type of activity had taken place and the time it took, as well as its purpose in relation to mobilization, performance and recovery. The participants also had to state where the reported activity took place as well as its aim or target group according to three alternatives: work, private activity or partner/child/home. For each time span they were encouraged to give information on who was perceived to be responsible for the activities (with three alternatives given: "You are chiefly responsible", "The responsibility is shared", or "Someone else has the chief responsibility for the activities conducted). Every time span was concluded by an assessment of the participant's general perception of the 24-hour period (Did the day leave you feeling happy and satisfied?).

The diary study was completed by a follow-up group conversation with all participants, which took place a couple of months later. Preliminary interpretations of the different parts of the diary were presented and discussed among the participants. This session, which lasted just above two hours, was recorded and transcribed literally.

\section{Field material}

The presentation of the material encompasses two levels. The first level includes all participants and provides a general 24-hour picture involving the two arenas of work and non-work. This part concludes with the evidence of women aged between 30 and 45 years. The material is presented under our conceptualized headings (i.e. themes identified in the material): Layering and On Stage, Recovery from Work? and Second and Third Shifts. The last heading solely comprises experiences from women aged between 30 and 45 years. After this, our presentation goes over to focusing entirely on the women of this group and concludes by specifying their experiences. This is done by means of four vignettes with the following headings: Time, Distraction, Nomads and Project Leader.

\subsection{Layering and on stage}

The participants generally described that their everyday work had been characterised by increased work intensification. The previous work ethos of the company that, according to the participants, stood for 
concern and community was no longer a reality. Since the spirit however lived on as a romantic retrospective image of how it used to be, it still formed an essential part of the workplace identity.

Due to the growing intensity ascribed, caused by the fact to the new task kept being added without replacing old tasks, there was no longer any time to cultivate this spirit. One of the examples provided by the participants was that new job evaluations or check-up forms were introduced while keeping the old ones. In other words, the general increase of work was caused by layered administrative procedures. The growing internal pressure was also linked to the increasing documentation of each activity. Parallel to these changes, according to the participants, most work elements were now subject to surveillance and direct assessment. A trend towards greater transparency, literally by the physical visibility of open-plan office landscapes, glass partitions, registering of pauses and of leaving work, as well as due to more detailed work performance measurement. The experience of current performances as being taking place both visibly and "front stage" was underlined. In our interpretation, the increasing work intensity can be related to these two dimensions: the relation between new and old tasks following a layering principle and the stronger feeling of being in the limelight of a front-stage position

\subsection{Recovery from work?}

The company's working hours are generally regulated, few employees leave the workplace later than 4.30 p.m. Everyone is supposed to be able to rest, recharge and return to work fully recovered the next day. This is also how most participants described their weekdays. The individual strategies for recovery from work varied from walking the dog and doing physical exercise to watching TV or being busy with their tablets. Social interaction at work was an essential factor affecting the recovery strategy. Working hours were largely characterized by social interactions with customers and work meetings of various kinds. The recovery strategies all shared one-dimension, social activities outside work were often avoided. Hence, recurrent descriptions of recovery from a socially overloaded working day included trying to avoid unnecessary social activity.

The lack of internal recovery could, however, be compensated for by well-functioning external recovery. Some participants reported that the increased intensity at work also negatively affected their possibilities for external recovery. Regardless of occupational position, women between 30 and 45 years claimed that the intensity ran high all round the clock, leading to permanent low-intensive stress and limited recovery possibilities.

\subsection{The second and third shifts - focusing on the women's stories}

Women between 30 and 45 year (with parental responsibility) described the growing intensity of work, which absorbed them during work hours in the phases of mobilization and performance. These phases overlapped one another in that the mobilization in preparation for a future task began before they had completed the previous task. It also emerged from these talks that it even included mobilization in anticipation of domestic duties. Women with parental responsibility reported a lack of possibility to make use of their leisure time for recovery. On the contrary, they described a situation where the intensity even might increase when moving from the work to the non-work sphere.

To this was added that coping with daily hassles deriving from the home and family sphere followed them into the work sphere, either as lingering mental representations, or rather as continuous organizing and planning for a near future. This primarily expressed itself mentally as well as concretely, in that the participants were handling various minor problems or predicted future ones.

The participants emphasized that they themselves and their partners shared the work carried out at home equally. Diary notes also confirmed that this also applied to which partner had chief responsibility during weekends. A closer analysis of the diary notes showed, however, that an overwhelming majority of female activities during leisure time could be related to (or directed towards) partners, family and children.

The follow-up talk about the diaries strengthened the picture that the major responsibility for the organizing, follow-up and planning of activities—during work and non-work hours-rested on the shoulders on the women in the study rather than to the men. It also emerged that, even during work hours, women, but not men, maintained a feeling of responsibility for organizing and planning activities outside work.

For the lack of a better word, what the women described was "project management". They thus provided a further dimension of recurrent mobilization during work hours as well as leisure time - a mobilization specially attached to this project manager role. 
Apart from sleep, there were few occasions and situations benefiting recovery mentioned by the participants. As they also found recovery hard to define, it acquired certain mythical forms. Most of them wanted to relate the process to specific environments that were supposed to symbolize peace and harmony, like the sea or the forest. Even if space had been found in everyday life for these rather fictional representations, they never comprised other people. Instead, they were all about being on one's own and having time at one's own disposal.

The situations and occasions found appropriate for recovery involved physical exercise. As such opportunities did not emerge out of nowhere, they required organizing. By getting up one hour before the rest of the family, for example, possibilities were created to do exercises for thirty minutes. The most common "recovery activity" was, however, surfing on their smart phone or tablet. Even though they highlighted this strategy, the participants argued that it was only a matter of distraction. Nonetheless, whenever gaps occurred in the daily routines, they were filled by smartphone activity.

Altogether, the material revealed a number of problems related to recovery among women between 30 and 45 years of age. Out of the analysis, a picture emerges of women perceiving themselves as being constant project managers for activities taking place during work-free hours. Taking responsibility for the home and for time beyond work, as illustrated by the long-arm-of-the-home metaphor, also turns up during work hours. In spite of reporting sharing domestic activities equally, taking the responsibility and following it up entailed constant mobilization leading in turn to constant energy consumption - the third shift. In the following text, four different vignettes linked to recovery and to the reported 24-hour stories are presented.

\subsection{Four vignettes linked to the 24-hour story}

The following four vignettes, Time, Distraction, Nomads and Project Manager, derive from the overarching theme of the material. These vignettes were chosen as good representative illustrations of the stories told by participant women between 20 and 45 . Each vignette is concluded by a brief interpretation before the start of the next.

\subsubsection{Time}

Kajsa: On a good day I get up at five and try running on the treadmill for half an hour. I'm finished by half past five. Wake the children half past six. Make sure they are awake and have their breakfast. Then I drive to work. Trying to arrive at half past seven now that I'm working half time, which I see as my salvation. Get home by three at best. Start making the evening meal, then we eat at four. We usually get off by five, taking the kids to their training; both of them play ice hockey. Drive away, leaving one child, home again, picking up the other. Then back to pick up the first one. If I'm lucky I can drive home and start preparing another evening meal in between. If I'm super lucky maybe both of them have training at the same time, and then I can do some jogging. We then get back home usually about half past eight. Have another round of eating, trying to get to bed between half past nine and ten. In between, washing up, doing the laundry, cooking again. So it goes.

Kajsa's 24-hour story comprises three distinct parts: paid work, non-work and sleep. What appears to be lacking is the balance between mobilization, performance and recovery. Kajsa's description is concentrated to the mobilization and especially, to the performance phase. No breathing-space or gaps for recovery [see 12] exist, and the different activities overlap round the clock. There is no focus whatsoever on recovery. Running the treadmill between 05.00 and 05.30 is the only activity that might be regarded as recovery. The importance of external recovery is specially underlined in research on recovery from work $[16,30]$. For Kajsa, time in the non-work sphere is not a question of recovery from work but of mobilizing and performing within the framework of the second shift [19]. It can also be assumed from Kajsa's story that some kind of organizing, planning and project management is required to make the second shift work. In Smeby's [33] words, there is need for a third shift.

\subsubsection{Distraction}

Mari: Perhaps as long as I stick to the mobile phone, it might lead to recovery. But since I get so many impressions everywhere, it seems to counteract such things.

Petra: That's me, as a matter of fact. Because I can sit watching a TV series I like very much, and it still doesn't seem enough. This is how it is: I have missed my favourite series because I keep scrolling on Facebook. I don't even think it's fun!! It's so strange, that behaviour.

Lisa: The concentration has broken down. I can't watch a film, for example. I have no patience for it. I just look at things that are sort of max one hour long. 
The small gaps that a few participants did mention were quickly filled by using smartphones. Research on the exact impact of smartphones on recovery is contradictory. A study by Rieger et al. [29] show that smartphones used during brief time gaps may have a recovering function. However, the same studies also show that "While mobile devices seem to provide the potential to amplify autonomy and control-related positive outcomes, they simultaneously endanger relaxation in response to fatigue." [29, p. 173].

In spite of the existence of occasions without immediate demands or expectations, the focus is still directed "outwards" with a view to doing more, gathering more information, or just finding distraction. The activity appears to need to be sufficiently "demanding" so as not to cause losing attention temporarily. Earlier studies of recovery from work have shown that an activity has to be perceived as meaningful for the focus to shift and become concentrated [12]. For these participants, the difficulty seems to be to maintain concentration and restrict their accessibility to impressions.

\subsubsection{Nomads}

Tina: One thing I think has become something like a demand, coming sort of from the way the labour market has turned out, is that ... you're expected all the time, on top of what you are just doing, to have some sort of plan for where to move from there. You have to be, sort of, your own career coach. "Where will you be in five years from now, how are you going to get there?" This, I think, is a more or less explicit demand on colleagues today, that you're supposed to be so terribly aware. All choices you make have to be so conscious. You're supposed to have strategies for where to move. It's as if everyone is expected to become a leader. I really think that's pretty demanding. Like a filter laid, sort of, on top of what you're already doing.

Annika: It's easy to think that people that are satisfied are a bit odd. It's somehow synonymous with lacking ambition.

Working life appears to possess an implicit expectation for moving continuously. The old psychological contract was abandoned a long time ago [3]. When occasion arises, the individual should be prepared to move on, either aside or rather upwards in the organization. It is considered unambitious if one's goal is not to become a boss or, at least, make a career, Tina suggests. Thus, there emerges an extra layer of perceived demands which are not explicit, nevertheless, these are the real stressors in Tina's and Annika's working life.

\subsubsection{Project manager}

Researcher: Are you the project manager?

Frida: A hundred percent. I find it hard to remember things, so I enter them into the phone. When the phone calls at 06.30 , it says "gym bag for the boys" One of them needs it two days a week, and the other one. It may be one of those things that just come up. "Shit, I must do this today". Then you enter it, or it will be gone. It may be calling the piano teacher or fixing a ride to the training. It could be anything.

Therese: But we share the responsibility; we share driving to the training, and we share to some extent cooking and such things. But I'm still the one who makes sure that something happens. Now we'll have to do this, now we must remember that, now's that training, in the weekend it's the party for Emma. It would have been nice to be able to let it go sometimes, but right now I keep swimming in my little bubble. Hoping that everything will be $\mathrm{OK}$.

Exactly as in the Time vignette, in this 24-hour story, mobilization and performance (not recovery) are at the core round the clock, throughout the week there is a constant flow of daily hassles [21, 22]. The actual time devoted to these seem to be equally distributed between the women themselves and their partners. Nevertheless, they agree that something is added that goes beyond visible work (performance) such as picking up or leaving children, or food shopping, or home cleaning. Something is added that is about organizing and planning for the various activities to be performed in the second shift. The participants illustrate a project management, which is also energy-consuming and very rarely contains situations where this responsibility can be dropped.

\section{Discussion}

We entered the field with a fairly instrumental view of recovery. Somewhat simplified, our perception built on the phases of mobilization, performance and recovery and on the assumption that these phases formed a simple chronological chain. Even though this order of things agrees with the work cycle in its simplest form [26, 37], we soon realized that this picture of a dynamic process whose activity level is continuously adapted to the demands of the environment is not as clear-cut in practice as in theory. Instead, these phases are mixed, with several different 
tasks (past, present and future) from both the first, second and third shifts creating complex dynamics. The temporal relation between mobilization, performance and recovery may be viewed as an ideal type, where deviations in practice may emerge in a concrete comparison.

The relation between work and non-work has often been understood as work paves the way for leisure and that leisure, by recreation and rest, should restore the energy level of the worker. In recent decades, this clear division between work and non-work has become less distinct and more overlapping [1, 4, 27], which was also supported by the participants of this study. None of them brought their work home, thus supposedly modern relationship between work and non-work was not found in this study. What rather emerged was perceived higher intensity of jobs performed at the workplace, a change in climate with intensified work demands. The chances of internal recovery [16] were reduced as new tasks did not automatically replace old ones (which tended to remain) and because of the greater transparency which moved the performance front stage [see e.g. 17].

The experience of growing intensity at work probably reflects a general trend in working life. Nevertheless, our interpretation of the interviews suggests that the work situation was still highly manageable. All the women aged 30-45 with parental responsibility participants described impeded recovery. They now lacked possibilities for internal recovery, and the external recovery available were claimed to be highly limited, since the "non-working" hours were depicted as a continuous stream of requirements that never gave in to a palpable need for finding time for themselves. Their 24-hour stories thus highlighted the inaccessibility of both internal and external recovery.

Taking the whole 24-hour story into consideration, a most interesting finding turned out to be the demands from home work and the ever-present demand to plan and organize for this, which reduced this group's chances of recovery. As demonstrated by previous research, neither time nor place after work functioned as recovery space for women [14, 15]. For some of them, stress rather increased when the first shift was replaced by the second. In contrast to Frankenheauser's [15] studies, this study's participants highlighted the equality of their partner relation, with two adults sharing the tasks in the second shift. They were quite explicit when it came to the actual performance, emphasizing that the time devoted to working with second shift tasks was quite equally distributed. The great dividing-line turned out to be linked to the organizing and planning of the second shift. In this respect, the women reported to take the main responsibility. To be the sole responsible for the project manager role apparently consumed great part of the mental resources for these women. Not only did it fail to provide any possibility for recovery during the work-free hours of the day, but it also appeared to have a lingering effect during working hours. One possible way of describing this is as the long arm of home. This description could then form a complement to the metaphor of the long arm of the job [see 4], in the sense that even if an employee has literally left the workplace, the work itself has a lingering mental effect. In other words, this is a similar process, even if it goes "in the opposite direction".

\subsection{Methodological reflexions}

Our aim for future research is to broaden the understanding by including other types of professions and industries. Furthermore, there is a need for additional in-depth knowledge and understanding of the group of males with children living at home, whose stories are not sufficiently prominent to be compared with those of the women.

Nevertheless, we have faithfully stuck to our material without enforcing any beforehand given models on it. Instead, we have exploratory changed and sensitively adapted our approach to the findings. We have endeavoured to fulfil the knowledge requirements regarding interpretative credibility and usefulness. Our arguments for the credibility of our interpretation are primarily related to the following aspects: the initial readings of the material were undertaken individually and were followed by mutually exchanging our empirical interpretations; method triangulation (group interviews and diaries) were conducted. The definite bearing of our interpretations on other theories was ensured; and the vignettes were used to enable taking a stand between our interpretation and primary data. Furthermore, the diary study was finalized by a follow-up talk, thus offering both an opportunity for gathering material as well as providing an occasion for validation. We also wish to assert that our interpretations are highly action relevant. On different levels and within different spheres, the present study sheds light on problems related to general recovery and issues regarding equality. Both of these are (especially from the integration point of view) of concrete importance for the practice, by starting from individual prerequisites and demands, while including the vision of a sustainable alternative. 


\subsection{Limitations}

Although the authors have strived to fulfill the knowledge requirements regarding interpretative credibility, the study still has some limitations. First, the number of participants in the entire study was restricted thirty persons, whereof only eleven were women in the age range of interest for the study, $30-45$ years. However, the limited number of participants is still in line with an explorative qualitative inquiry, i.e. research concerned with the quality and texture of experience. A second possible limitation in regard to the transferability of the findings stems from national and occupational context. The study was carried out in Sweden, exclusively with participants from a regional office of an insurance company. How the "third shift" is perceived and constructed in other contexts we do not really know. Future research could expand upon the current research and explore other professionals, industries, and cultures.

\section{Conclusions}

While recovery from work offers a highly important perspective, such an approach may simultaneously overlook other aspects of the total burden of work. In the present study, the most obvious issues concern equality in the non-work sphere. To consider nothing but what is visible and palpable simplifies the understanding of both work [see 4] and nonwork arenas. As a precondition for external recovery, there is evidence that Smeby's [33] breakdown of the second shift and development of the third shift are theoretically beneficial for understanding different preconditions and the way they affect the possibility of recovery. The stories should also pose a number of questions to the current practice, about equality in relationships but also about the way employers and organizations may relate to the variation in individuals' life situations as well as to temporary needs and conditions. How does the dialogue run between employers and employees with regard to life phase, 24-hour stories, career, and their joint mission translated into everyday tasks?

\section{Conflict of interest}

None to report.

\section{References}

[1] Allvin M, Aronsson G, Hagström T, Johansson G, Lundberg U. Gränslöst Arbete - Socialpsykologiska Perspektiv på det Nya Arbetslivet. Stockholm: Liber; 2008.

[2] Amaro J, Ubalde-López M, Lucas R. History of workrelated health problems in a population-based sample of women: An exploratory factor analysis. Work. 2021;68(3): 563-576. DOI: 10.3233/WOR-203394

[3] Aronsson G. Hellgren J. Isaksson K. Johansson G. Sverke M. Torbiörn I. Arbets- och organisationspsykologi: individ och organisation i samspel. Stockholm: Natur \& Kultur; 2012.

[4] Aronsson G, Nylén EC, Ishall L, Lindfors P, Sverke M. The long arm of the job - The work characteristics and recovery window in social welfare work. International Journal of Workplace Health Management. 2019;12(1):15-27.

[5] Bakker AB, Demerouti E. The Job Demands-Resources model: State of the art. Journal of Managerial Psychology. 2007;22(3):309-328

[6] Barbano LM, da Cruz D. Time use purchasing power, and job satisfaction: Correlation and comparison between working women with children and working women without children. Work. 2019;62(4):265-257. DOI: 10.3233/WOR192891

[7] Bergman A, Palm K, Rosengren C. Aktivitetsdagboken. 2017. ISBN 978-91-7063-769-8.

[8] Brosschot JF, Geurts SAE, Kruizinga I, Radstaak M, Verkuil B, Quirin M, Kompier MAJ. Does unconscious stress play a role in prolonged cardiovascular stress recovery? Stress and Health 2014;30(3):179-187. DOI: 10.1002/smi.2590

[9] Cropley M, Rydstedt LW. Andersen D. Recovery from work: testing the effects of chronic internal and external workload on health and well-being. BMJ. 2020;74:919-924. DOI: $10.1136 /$ jech-2019-213367

[10] Cropley M, Zijlstra FRH. Work and Rumination. In: J. Langan-Fox. C.L. Cooper. Editors. Handbook of Stress in the OccupationsEdward Elgar Publishing Ltd: UK. 2011.p. 487-503. ISBN 9780857931146.

[11] Ejlertson L, Heijbel Ejlertsson G, Andersson I. Recovery, work-life balance and experiences important to self-related health: A questionnaire study on salutogenic factors among Swedish health care employees. Work. 2018;59(1):155-163. DOI: 10.3233/WOR-172659

[12] Ericsson U, Rydstedt LW, Pettersson P, Augustinsson S, Aronsson G. Återhämtning bland hockeyspelare i Tre Kronor, Nattarbetande bagare och skolledare. Arbetsliv i Omvandling.2016. No 22016.

[13] Frankenhaeuser M, Lundberg U, Fredriksson M, Melin B, Tuomisto M, Myrsten A-L. Stress on and off the job as related to sex and occupational status in white-collar workers. J. Org. Behav. 1989;10(4):321-346.

[14] Frankenhaeuser M. Kvinnligt, manligt, stressigt. Förlags AB Wiken, Höganäs. 1993.

[15] Frankenhaeuser M, Lundberg U, Chesney M. Editors. Women Work and Health. New York: Plenum; 1991.

[16] Geurts SAE, Sonnentag S. Recovery as an explanatory mechanism in the relation between acute stress reactions and chronic health impairment. Scandinavian Journal of Work Environment \& Health. 2006;32(6):482-492.

[17] Goffman E. The Presentation of Self in Everyday Life. New York: Doubleday Anchor books. 1959.

[18] Hobfall SE. Conservation of resources: A new attempt at conceptualising stress. American Psychologist, 1989;44(3): 513-524. 
[19] Hochschild AR. The Time Bind. New York: Metropolitan Books. 1997

[20] Hochschild AR. The Second Shift. Working Parents and the Revolution at Home. New York: Viking. 1989.

[21] Larsson G, Berglund AK, Ohlsson A. Daily hassles, their antecedents and outcomes among professional first responders: A systematic literature review. Scandinavian Journal of Psychology. 2016;57(4):359-367

[22] Lazarus R, Folkman S. Stress: Appraisal and Coping. New York; Springer; 1984

[23] Linden W, Earle TL, Gerin W, Christenfeld N. Physiological stress reactivity and recovery: conceptual siblings separated at birth? Journal of Psychosomatic Research. 1997;42(2):117-135.

[24] Lundberg U, Mårdberg B, Frankenhaeuser M. The total workload of male and female white-collar workers as related to age, occupational level, and number of children. Scandinavian Journal of Psychology. 1994;35:315-327.

[25] McEwen BS. Stress, adaptation, and disease: Allostasis and allostatic load. Annals of the New York Academy of Sciences. 1998;840(1):33-44.

[26] Meijman TF, Mulder G. Psychological aspects of workload. In: P.J.D. Drenth H. Thierry C.J. de Wolff. Editors. Handbook of Work and Organizational Psychology: Vol. 2, Work Psychology. 2nd edition. Hove, UK: Psychology Press; 1998. P. 5-33.

[27] Nippert-Eng C. Home and Work: negotiating boundaries through everyday life. Chicago: University of Chicago Press. 1996.

[28] Pennbrant S. Dåderman A, Job demands, work engagement and job turnover intentions among registered nurses: Explained by work-family private lite inference. Work, 2021;66(4):1157-1169. DOI: 10.3233/WOR-213445

[29] Rieger D, Hefner D, Vorderer P. Mobile recovery? The impact of smartphone use on recovery experiences in waiting situations. Mobile Media \& Communication. 2017;5(2): 161-177

[30] Rydstedt LW, Cropley M, Devereux J, Michalianou G. The effects of gender, long-term need for recovery and trait inhibition-rumination on morning and evening saliva cortisol secretion. Anxiety, Stress \& Coping. 2009;22(4): 465-474
[31] Försäkringskassan. Sjukfrånvarons utveckling 2017 [Internet]. Stockholm: Försäkringskassan; 2017. Socialförsäkringsrapport; 13.

[32] Sluiter JK, Frings-Dresen MHV, van der Beek AJ, Meijman TF. The relation between work-induced neuroendocrine reactivity and recovery, subjective need for recovery, and health status. Journal of Psychosomatic Research. 2001; 50(1):29-37.

[33] Smeby KW. Likestilling I det tredje skiftet. Heltidsarbeidende småbarnsforeldres praktisering av familieansvar etter 10 uker med fedrekvote [Dissertation]Doktorsavhandling, Trondheim: NTNU; 2017:226

[34] Statistiska Centralbyrån. Nu för tiden. En undersökning av svenska folkets tidsanvändning 2010/11.Stockholm: Statistiska Centralbyrån; 2012. Levnadsförhållande rapport; 123.

[35] Theorell T. Det svenska 1990-talet ur ett stressmedicinskt perspektiv. Arbetsmarknad \& Arbetsliv. 2009;15(4): 204-221.

[36] Ursin H, Eriksen $H$. The cognitive activation theory of stress. Psychoneuroendocrinology. 2004;29(5):567-592

[37] Zijlstra FHR, Cropley M, Rydstedt LW. From recovery to regulation: An attempt to reconceptualise "recovery from work". Stress and Health. 2014:30(3):244-252.

[38] Zoupanou Z, Cropley M, Rydstedt LW. Recovery after work: The role core beliefs in the unwinding process. PLoS ONE. 2013:8(12):1-9.

[39] Zopanou Z, Rydstedt LW. Do Work Beliefs Moderate the Relationship Between Work Interruptions, Wellbeing and Psychosomatic Symptoms? Europe's Journal of Psychology. 2017:13(2):214-230

[40] Zopanou Z, Rydstedt LW. The mediating and moderating role of affective rumination between work interruptions and well-being. Work. 2019;62(4):553-561. 